\title{
Complete Distal Biceps Rupture in a 55 year-old female
}

\author{
Zubair S. Chaudry ${ }^{*}$, Eric J. Yakish², Corey R. Wells ${ }^{1}$, Jacob J. Bingham ${ }^{1}$ and Carl Y. Seon ${ }^{1}$
}

*Correspondence: chaudryzs@Upmc.edu

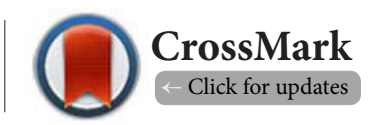

'Department of Orthopedic Surgery, UPMC Hamot, Erie, Pennsylvania, USA.

${ }^{2}$ Department of Orthopedic Surgery, Mid-Atlantic Permanente Medical Group, Rockville, Maryland, USA.

\begin{abstract}
Distal biceps tendon ruptures are relatively rare injuries in the female population, especially complete ruptures. As a result, the literature is limited on the subject. We report a case of a 55 year-old female, bus driver, with a complete distal biceps tear. She experienced a pop in her dominant arm while operating a compression hand brake. Surgical repair was performed for the distal biceps tendon through a single transverse incision approach using the BicepsButton (Arthrex, Naples, FL) technique. Reasons for biceps ruptures are multifactorial including: degenerative/age-related changes, mechanical stresses, ischemia, tobacco use, steroid use, and concomitant inflammatory arthropathies. This patient's history of rheumatoid arthritis and high-dosage steroid use coupled with her occupation likely contributed to her pathology. Given that these are rare injuries, it is important to understand and identify the clinical presentation as well as the risk factors that predispose patients to develop such injuries.
\end{abstract}

Keywords: Complete, distal biceps tear, rupture, female

\section{Introduction}

Complete distal biceps tears are relatively rare injuries, with a reported incidence of 1.2/100,000 [1] and account for 3-10\% of all biceps injuries $[2,3]$. These tears predominantly occur in men (93\%) aged 40-60 [4] and classically present after eccentric load application with the arm forced into extension from flexion $[1,4]$. Patients with complete tears consistently present with acute pain in the antecubital fossa and variably present with pain/weakness with flexion and supination [4]. Diagnosis occurs with advanced imaging coupled with the following physical exam findings: the hook test, biceps squeeze test, ecchymosis, and reverse Popeye sign [5].

These tears occur rarely in the female population, and thus, the literature is limited on this subject. Jockel et. al. reported on the largest case series of these patients noting 15 distal biceps tears in 13 women, with only two of these tears being complete [4]. Very few cases have been identified throughout the literature $[4,6,7]$.

\section{Case presentation}

A 55-year-old, right-hand dominant, female, employed as a bus driver for a local school system, presented after an injury to her dominant arm while working. She operates a compression hand brake that requires pushing/pulling many times throughout the day. On one occasion operating the brake, she experienced a pop in her dominant arm as she moved her elbow from a flexed to an extended position. She subsequently experienced pain in the antecubital fossa. Before the injury, she completed a high dose prednisone taper as she was suspected to have giant cell arteritis. With further testing, she was diagnosed with rheumatoid arthritis and placed on leflunomide therapy. She reported no other comorbidities.

She presented two weeks from the time of injury. On exam, she displayed no ecchymosis at the antecubital fossa but endorsed pain with palpation overlying this area. Physical exam showed pain/weakness elicited with resisted flexion and supination and a positive hook test. Plain radiographs were unremarkable. MRI revealed full thickness distal biceps rupture with $1.5 \mathrm{~cm}$ retraction (Figure 1). The patient was amenable to operative intervention, noting the importance of limiting residual weakness in her dominant extremity for both her work and daily recreational activities.

A single transverse incision was made distal to the elbow flexion crease. The distal biceps tendon was identified, noting it to be tethered by the lacertus fibrosus with the tendon sheath still intact (Figure 2). The tendon itself was completely detached from 
the radial tuberosity. The distal biceps tendon was prepared and whip-stitched with a FiberLoop suture (Arthrex, Naples, FL).

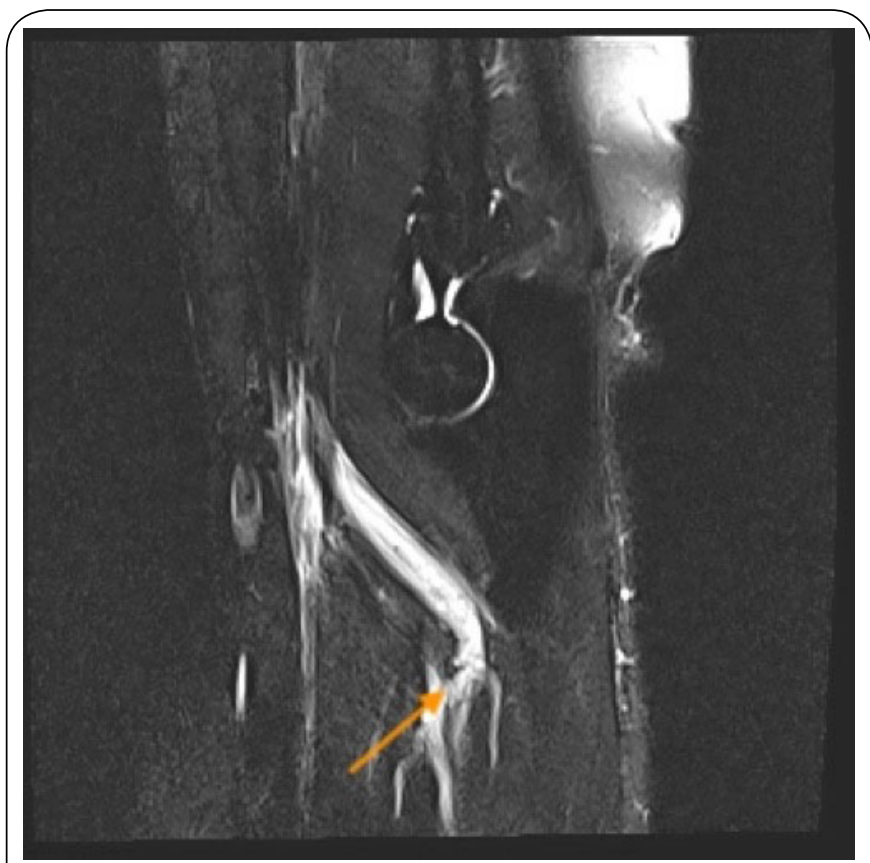

Figure 1. Sagittal, T2-weighted image of the right elbow. The arrow indicates ruptured biceps tendon stump.

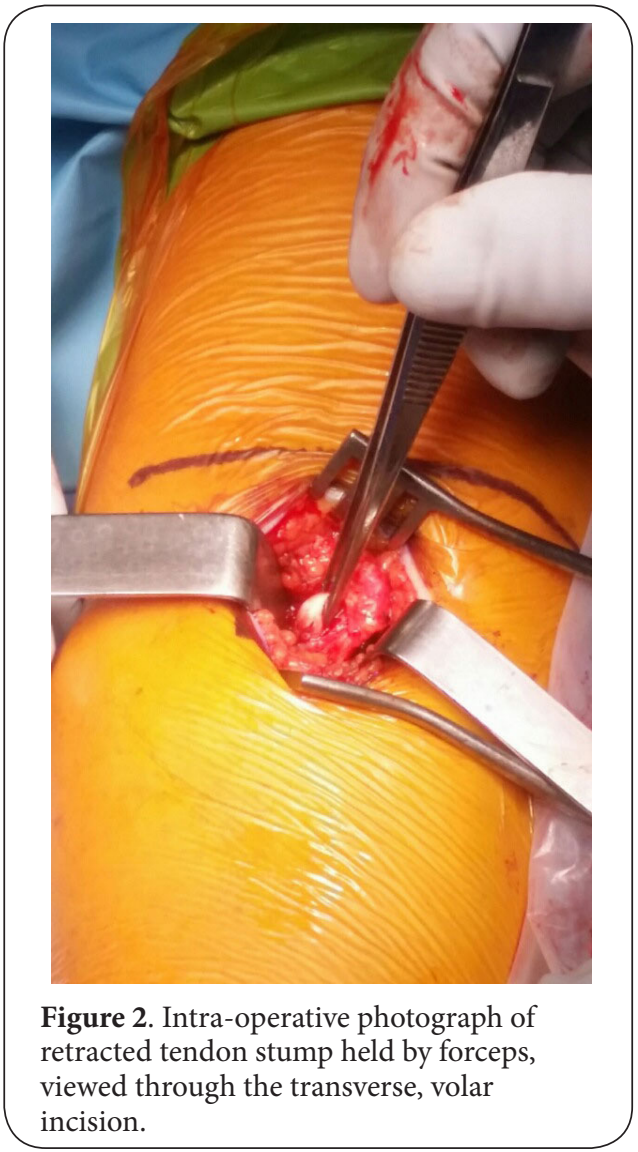

The sutured tendon was passed through the BicepsButton

(Arthrex, Naples, FL), which was inserted at the radial tuberosity through an $8 \mathrm{~mm}$ drill hole. The button was flipped on the far cortex, and confirmed with fluoroscopy. The suture limbs were tensioned. One limb of the suture was passed through the tendon with a free needle and tied to the other limb securely. The repaired tendon was seated within the drill hole with appropriate tension (Figure 3).

The patient experienced numbness in the lateral antebrachial cutaneous nerve distribution for two months post operatively, a described complication in $9.8 \%$ of patients undergoing this procedure through a single incision [8]. The condition resolved spontaneously as expected. She gained symmetric flexion/extension and pronation/supination compared to the contralateral side. She began strengthening with physical therapy at 2 months postoperatively. She returned to work after her 7 month follow up for light duty and was released to full duty without restriction at 8 months post operatively.

\section{Discussion}

Distal biceps tears are rare injuries in the female population. When they occur, they are most often partial tears. This makes the diagnosis difficult because of variability in presentation

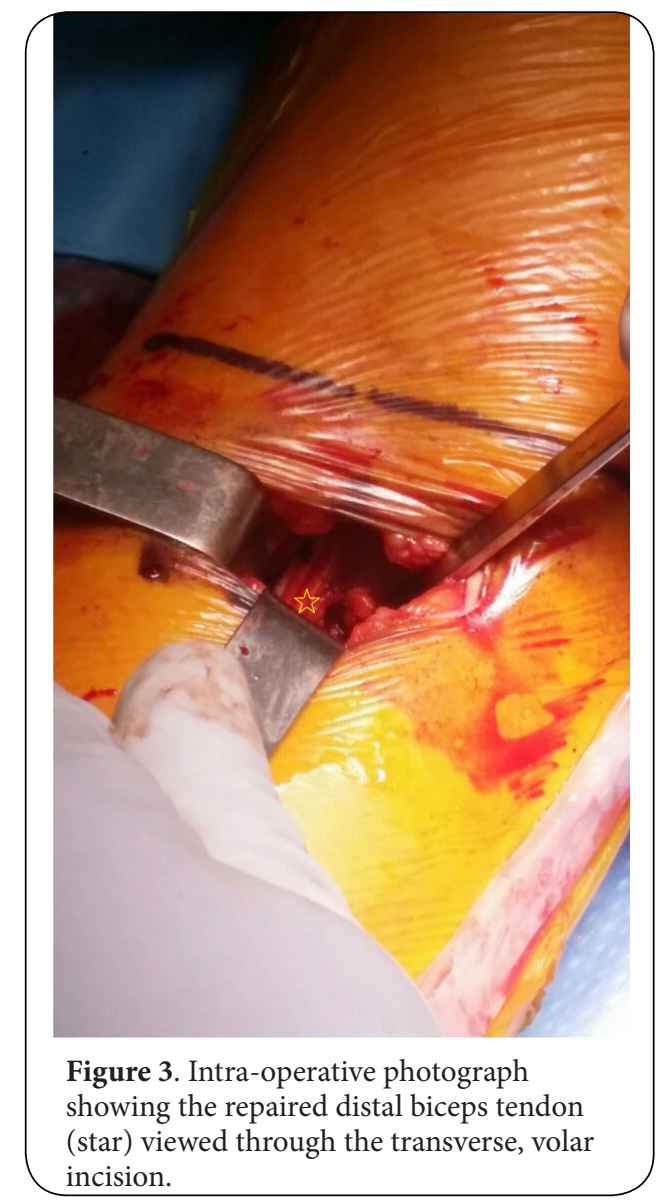


and subtlety of symptoms [4]. In these cases, MRI studies show thickening of the biceps tendon with irregular contours and increased signal uptake in the area [9]. Bicipitoradial bursitis is seen in up to $55 \%$ of patients with partial tears [8]. Additionally, bone marrow edema and cystic changes in the radial tuberosity can be seen in up to $50 \%$ of patients with partial tears [9].

Reasons for biceps ruptures are multifactorial including: degenerative/age-related changes, mechanical stresses, ischemia, tobacco use, steroid use, and concomitant inflammatory arthropathies. Aging is associated with increased collagen crosslinking and decreased concentration of elastin, glycosaminoglycan, and water [4]. These changes result in a stiffer, lesscompliant tendon, more prone to injury [6]. Many patients report minor trauma that should not have been significant enough to cause a tear in a healthy tendon, supporting the idea that the tear is the final manifestation of a degenerative process [9].

Presumably, mechanical impingement of the distal biceps tendon occurs as the space for the tendon between the radius and ulna decreases in pronation compared to supination [10]. Boney irregularities and inflammation of the biceps tendon can exacerbate this impingement [9]. Bursitis visualized on the MRI for partial tears may further support the idea of impingement of the biceps tendon.

In combination with mechanical impingement, Seiler et. al. described a hypovascular zone within the tendon, placing this region at higher risk of rupture [10]. The tendon is divided into three zones: The area extending just distal to the musculotendinous junction (zone 1), the mid portion of the tendon (zone 2), and the tendon enthesis on the radial tuberosity (zone 3). Zone 1 obtains its blood supply from branches of the brachial artery and zone 3 receives its blood supply through branches of the posterior interosseous recurrent artery. Zone 2 , the hypovascular zone, receives its blood supply from the superficial paratenon, which contains contributions from both blood supplies [10].

Our patient received high doses of oral steroids prior to her injury. Strong correlation exists between the development of tendinopathy/ tendon rupture and corticosteroid use [11]. In vivo and in vitro studies have shown the negative influence of glucocorticoids on biomechanical properties of tendons, causing pathological changes in tendinocytes shortly after administration [12]. Both oral glucocorticoids and parenteral steroids show increased risk of tendon rupture in a doseresponse relationship $[11,12]$. Spoendlin et. al. found that greater than or equal to $20 \mathrm{mg} /$ day course of oral steroids may be sufficient risk for tendon rupture for a course less than 30 days [12].

Rheumatoid arthritis is an autoimmune inflammatory condition affecting the synovial membrane of joints and the synovial sheath of tendons $[13,14]$. Tenosynovitis manifests itself first, followed by invasion of the tenosynovium into the tendon. Angiogenesis within the synovium fuels this and further propagates this degenerative process, leaving it weakened [15]. Although no specific studies discuss the relationship of distal biceps tears and rheumatoid arthritis, it is well known that the disease process predisposes patients to tendon ruptures by the process described above. These occur most commonly in the hand but are not limited to this portion of the body [15]. Strunk studied degenerative changes within the proximal biceps in patients with rheumatoid arthritis, confirming the notion that bicipital tenosynovitis is a common finding in rheumatoid arthritis [14].

\section{Conclusion}

Distal biceps tendon tears rarely occur in women and usually present as partial tears. It is important for the clinician to understand the factors that can predispose patients to this pathology, and to recognize clinical signs/symptoms that might be indicative of a tear. This patient's rheumatoid arthritis, steroid use, and occupation all likely contributed to her pathology of a complete biceps tear.

\section{Competing interests}

The authors declare that they have no competing interests.

Authors' contributions

\begin{tabular}{|l|c|c|c|c|c|}
\hline Authors' contributions & ZSC & EJY & CRW & JJB & CYS \\
\hline Research concept and design & -- & -- & -- & -- & $\checkmark$ \\
\hline Collection and/or assembly of data & $\checkmark$ & $\checkmark$ & $\checkmark$ & $\checkmark$ & -- \\
\hline Data analysis and interpretation & -- & -- & -- & -- & -- \\
\hline Writing the article & $\checkmark$ & $\checkmark$ & $\checkmark$ & $\checkmark$ & -- \\
\hline Critical revision of the article & $\checkmark$ & $\checkmark$ & $\checkmark$ & $\checkmark$ & $\checkmark$ \\
\hline Final approval of article & $\checkmark$ & $\checkmark$ & $\checkmark$ & $\checkmark$ & $\checkmark$ \\
\hline Statistical analysis & -- & -- & -- & -- & -- \\
\hline
\end{tabular}

Acknowledgement and funding

None of the authors have received grant support or research funding for completion of this article.

Publication history

Editor: Antonio G Tristano, Medical Center Carpetana, Spain. Received: 24-Sept-2019 Final Revised: 28-Oct-2019

Accepted: 01-Nov-2019 Published: 11-Nov-2019

\section{References}

1. Safran MR and Graham SM. Distal biceps tendon ruptures: incidence, demographics, and the effect of smoking. Clin Orthop Relat Res. 2002; 275-83. I PubMed

2. Nayyar S, Quirno M, Hasan S, Rybak L and Meislin RJ. Rupture of the distal biceps tendon combined with a supinator muscle tear in a 51-year-old woman: a case report. Case Rep Radiol. 2011; 2011:515912. | Article | PubMed Abstract | PubMed FullText

3. Sutton KM, Dodds SD, Ahmad CS and Sethi PM. Surgical treatment of distal biceps rupture. J Am Acad Orthop Surg. 2010; 18:139-48. | Article I PubMed

4. Jockel CR, Mulieri PJ, Belsky MR and Leslie BM. Distal biceps tendon tears in women. J Shoulder Elbow Surg. 2010; 19:645-50. | Article | PubMed

5. Huber, FG. Arm. In: Delee JC, Drez D, Miller MD ed. Delee \& Drez's orthopaedic sports medicine: principles and practice, 3rd ed. Philadelphia, PA: Saunders/Elsevier. 2010; 1167-70.

6. Bauman JT, Sotereanos DG and Weiser RW. Complete rupture of the 
Chaudry et al. Journal of Rheumatology and Orthopedics 2019,

http://www.hoajonline.com/journals/pdf/2055-7000-6-1.pdf

distal biceps tendon in a woman: case report. J Hand Surg Am. 2006; 31:798-800. | Article | PubMed

7. Toczylowski HM, Balint CR, Steiner ME, Boardman $M$ and Scheller AD, Jr. Complete rupture of the distal biceps brachii tendon in female patients: a report of 2 cases. J Shoulder Elbow Surg. 2002; 11:516-8. | Article | PubMed

8. Amin NH, Volpi A, Lynch TS, Patel RM, Cerynik DL, Schickendantz MS and Jones MH. Complications of Distal Biceps Tendon Repair: A Metaanalysis of Single-Incision Versus Double-Incision Surgical Technique. Orthop J Sports Med. 2016; 4:2325967116668137. | Article | PubMed Abstract | PubMed FullText

9. Williams BD, Schweitzer ME, Weishaupt D, Lerman J, Rubenstein DL, Miller LS and Rosenberg ZS. Partial tears of the distal biceps tendon: MR appearance and associated clinical findings. Skeletal Radiol. 2001; 30:560-4. | Article | PubMed

10. Seiler JG, 3rd, Parker LM, Chamberland PD, Sherbourne GM and Carpenter WA. The distal biceps tendon. Two potential mechanisms involved in its rupture: arterial supply and mechanical impingement. J Shoulder Elbow Surg. 1995; 4:149-56. | Article | PubMed

11. Blanco I, Krahenbuhl S and Schlienger RG. Corticosteroid-associated tendinopathies: an analysis of the published literature and spontaneous pharmacovigilance data. Drug Saf. 2005; 28:633-43. | Article | PubMed

12. Spoendlin J, Meier C, Jick SS and Meier CR. Oral and inhaled glucocorticoid use and risk of Achilles or biceps tendon rupture: a population-based case-control study. Ann Med. 2015; 47:492-8. | Article I PubMed

13. Feldman M, Brennan FM and Maini RN. Rheumatoid Arthritis. Cell. 1996, 85:307-10.

14. Strunk J, Lange U, Kurten B, Schmidt KL and Neeck G. Doppler sonographic findings in the long bicipital tendon sheath in patients with rheumatoid arthritis as compared with patients with degenerative diseases of the shoulder. Arthritis Rheum. 2003; 48:1828-32. | Article | PubMed

15. Sivakumar B, Akhavani MA, Winlove CP, Taylor PC, Paleolog EM and Kang N. Synovial hypoxia as a cause of tendon rupture in rheumatoid arthritis. J Hand Surg Am. 2008; 33:49-58. | Article | PubMed

\section{Citation:}

Chaudry ZS, Yakish EJ, Wells CR, Bingham JJ and Seon CY. Complete Distal Biceps Rupture in a 55 year-old female. J Rheumatol Orthop. 2019; 6:1. http://dx.doi.org/10.7243/2055-7000-6-1 